\title{
Multidisciplinary Study of Cerebral Aging in Non-Human Primates
}

\author{
C.I. Fernández, E. Fermin*, R. Macías and L. Alvarez \\ Centro Iberolatinoamericano de Trasplante y Regeneración del Sistema Nervioso \\ *Centro de Investigaciones M edico Quirúrgicas \\ Ave. 25, No. 15805, Playa. Ciudad Habana, Cuba
}

It is well known that in humans, significant changes in cognitive function, postural control and motor coordination appear with age $/ 1 /$. Age-related memory decline has been described in non-human primates $/ 2 /$ as well as age differences in activity patterns $/ 3 /$. To obtain a better understanding of age-associated changes in these functions, we have begun studies that include: assessment of visual recognition memory using a delayed non-matching-to-sample (DNMS) with trial unique stimulus presentation carried out in a Wisconsin General Apparatus Test /4/; spontaneous motor activity patterns; CT scan and evoked potentials. Five groups of male rhesus monkeys (Macaca mulatta) were used, I (1-2 years old); II (3-6 yr); III (10-13 yr); IV (20-24 yr) and V (25-28 yr). Groups III-V were tested behaviorally, imagenologically and electrophysiologically, while groups I-II were used for the CT scan study only. Although animals of all ages had been trained to a common criterion on the basic DNMS task, performance deteriorates during basic learning and retention and when memory is challenged by increasing delay, similarly to what was reported by Presty et al. and others $/ 2,4 /$. The differential performance in aged groups across conditions of the DNMS task raises the possibility that several distinct cognitive abilities are affected in old monkeys, i.e. associative learning capacity (Acquisition Phase) and rate of decay of stored information (retention and delays).

Cortical density values obtained by CT scan (frontal, parietal and temporal cortices) showed a highly negative correlation with age. Also, distance between lateral ventricle anterior horns was increased with age, while distance between sylvian region and III ventricle was decreased in old animals. Both variations may be a consequence of cortical-subcorvical atrophy and ventricular dilatation $/ 5 /$.

Evaluated motor activities showed that their frequency and type as well as box position were influenced by age. Old monkeys assumed a more rigid posture pattern and less locomotor activity, in agreement with other reports $/ 3,6 /$.

Auditory brainstem potential wave latencies exhibited variations with age; we therefore suggest increasing the subject number to obtain more definitive conclusions.

Aged non-human primates show morphological and behavioral changes which can be associated with normal human aging; these animals may be the best model for studies on brain aging or associated neurodegenerative disorders such as Alzheimer's disease.

\section{REFERENCES}

1. World Health Organization. WHO Technical Report Series 1981; 665: 45-59.

2. Ridley RM et al. Brain Res Rev 1991; 16: 15-37.

3. Janicke B et al. Gerontology 1986; 32: 133-140.

4. Presty SK et al. Neurobiol Aging 1987; 8: 435-440.

5. Henderson G et al. J Neurol Sci 1980; 46: 113-136.

6. Draper WA. Science 1966; 151: 476-478. 

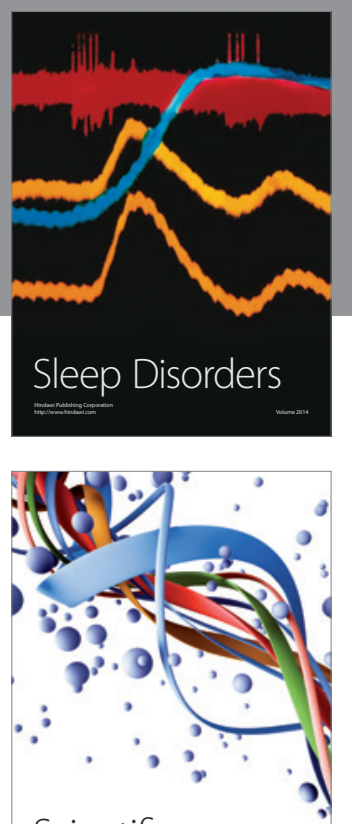

Scientifica
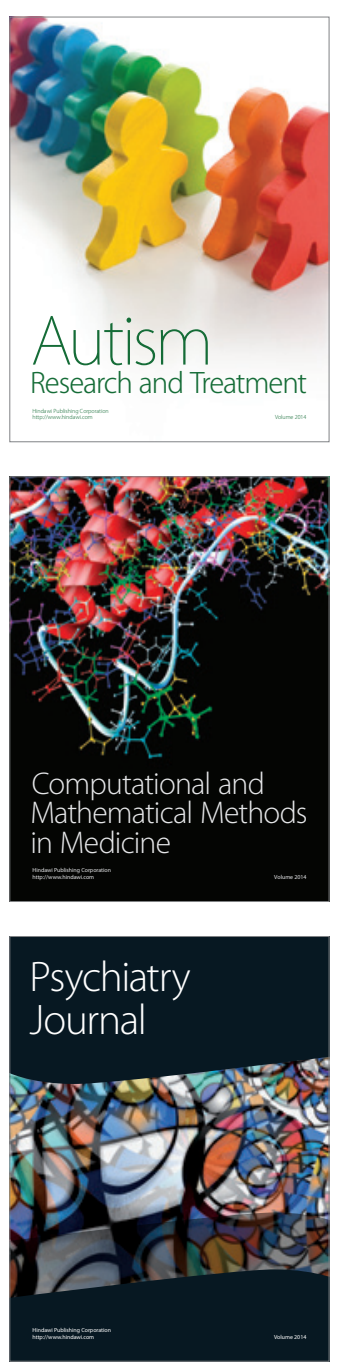
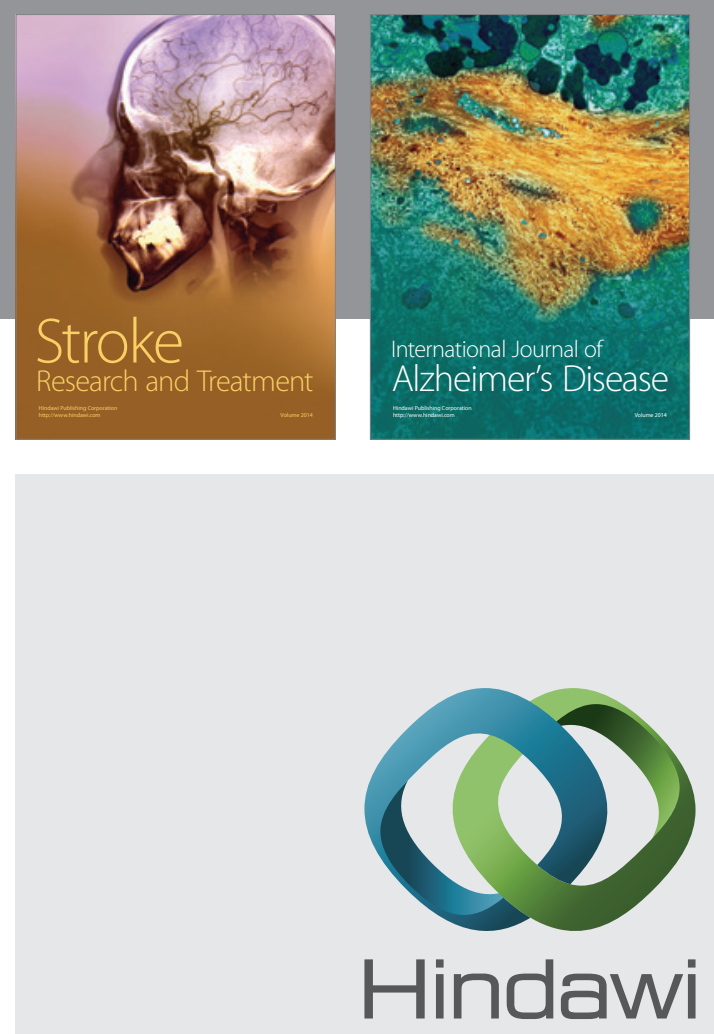

Submit your manuscripts at

http://www.hindawi.com
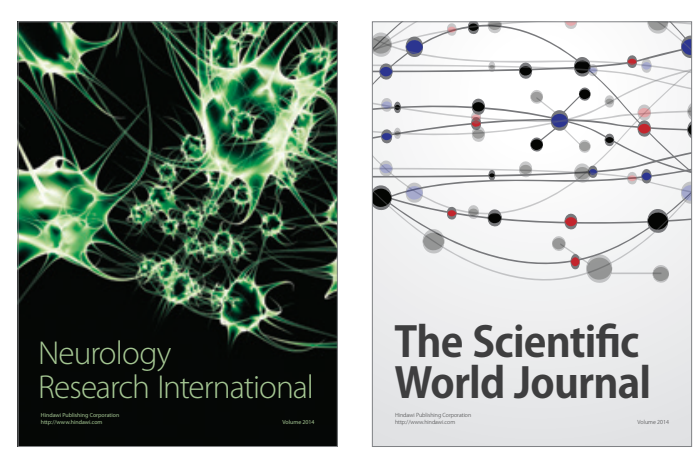

The Scientific World Journal

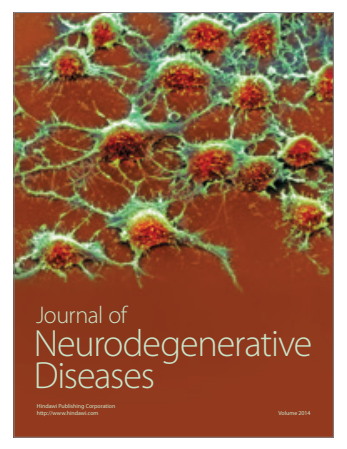

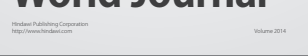

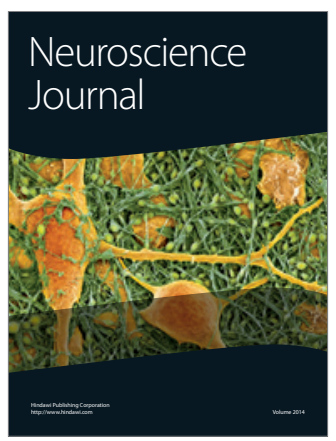

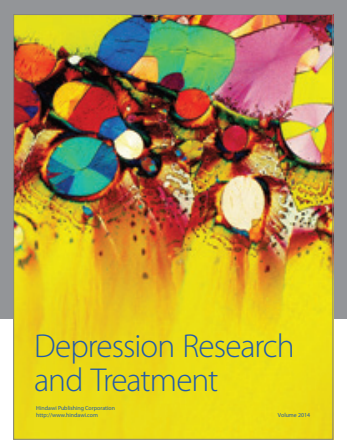
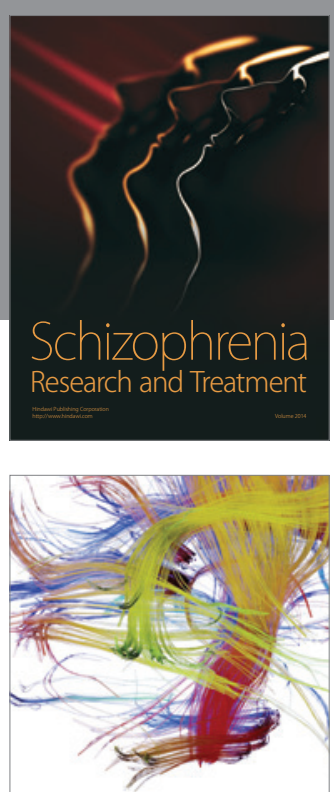

Brain Science

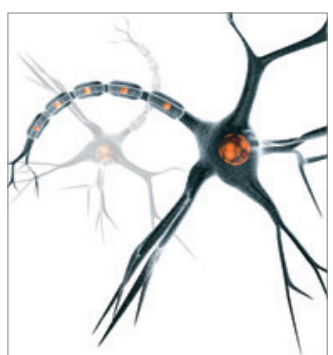

Neural Plasticity
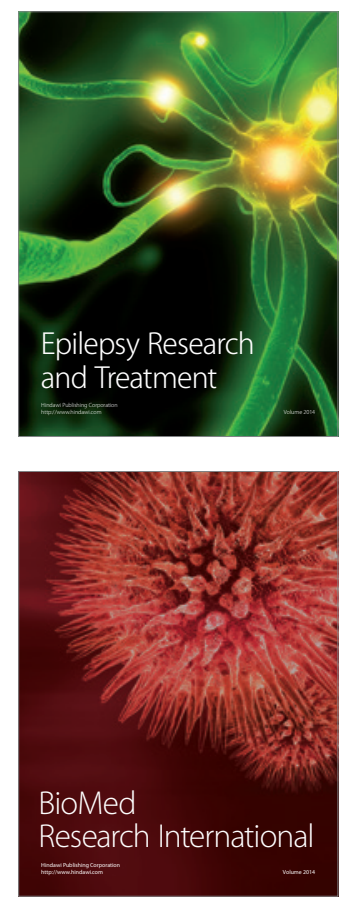

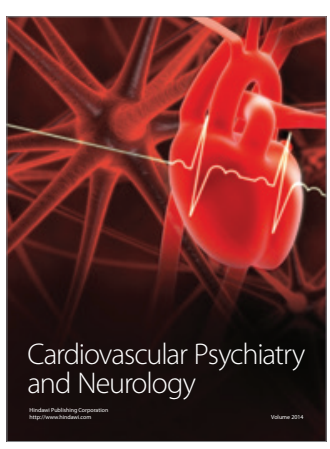

Parkinson's

Disease
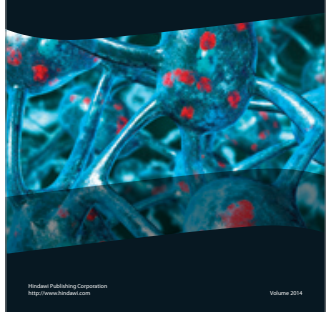